\title{
NUMERICAL STUDY ON THE RELEVANCE OF COLUMNS HIDDEN FAILURE MODES IN THE SEISMIC CAPACITY OF NON- DUCTILE RC FRAMES
}

\author{
B. Alfarah ${ }^{1} ;$ F. López-Almansa ${ }^{2}$; and S. Oller ${ }^{3}$ \\ ${ }^{1} \mathrm{PhD}$, Civil and Environmental Engineering Department, Technical University of Catalonia, Barcelona, bashar.alfarah@upc.edu \\ ${ }_{2}^{2}$ Professor, Architecture Technology Department, Technical University of Catalonia, Barcelona, francesc.lopez-almansa@upc.edu \\ ${ }^{3}$ Professor, Civil and Environmental Engineering Department, Technical University of Catalonia, Barcelona, sergio.oller@upc.edu
}

\begin{abstract}
In simplified seismic structural analyses, not all the deterioration modes are adequately considered. This work discusses the relation among the hidden failure modes of columns of non-ductile RC building frames and their global collapse mechanism. With this aim, a numerically efficient model is developed and implemented in OpenSEES. Two benchmark problems are analyzed with this model: the well-known Van Nuys Hotel and a prototype building designed for gravity loads only; in this last case, the results are compared with experiments on a one-third scale model. The obtained results confirm that simplified models grossly overestimate the building capacity.
\end{abstract}

Keywords: Seismic response, Non-ductile RC frames, Collapse mechanism, Axial deterioration, Shear deterioration.

\section{Introduction}

The nonlinear dynamic analysis of reinforced concrete $(\mathrm{RC})$ structures under strong seismic excitation is not a routine task, requiring an in-depth knowledge of the structural behavior for each performance level, principally near collapse. Moreover, reinforced concrete is a mixed material with highly complex nonlinear behavior; i.e. each structural element has several coupled deterioration modes, namely flexure, shear, and axial. Their interaction influences the entire structure and determines its global collapse mechanism. This issue is especially important in RC building frames designed without any seismic provision, since these buildings are highly vulnerable to severe earthquakes and exhibit important brittle deterioration and failure modes, i.e. shear and axial. This type of structures is commonly known as "non-ductile RC frame"; the influence of columns brittle deterioration modes is high, because the customary ductility requirements ("strong column-weak beam", and "critical regions confinement", among others) are not fulfilled.

Unfortunately, non-ductile RC frames are extremely widespread, even in seismic regions. This profusion is due to, among other reasons, underestimation of the actual seismicity, loose requirements of the past design codes, lack of fulfillment of the current codes, and poor construction practices. On the other hand, seismic design and analysis of actual buildings requires dealing with complex models, thus having many degrees of freedom. Moreover, costly nonlinear dynamic analyses are being more routinely used by designers; even Incremental Dynamic Analysis (IDA) has started being used. IDA [Vamvatsikos, Cornell 2002] consists in determining the dynamic structural response to one or several seismic inputs (accelerograms) scaled with increasing factors, thus requiring a huge number of operations. All these circumstances show that, in earthquake engineering, complex continuum mechanics-based formulations are not practical; as a result, simplified models are routinely considered. Often, such models are excessively abridged, e.g. accounting only for flexure deterioration modes; therefore, can lead to misleading results. Consequently, there is a strong need for models that combine numerical efficiency and accuracy, mainly with the consideration of the most relevant deterioration modes and their interaction.

This paper presents a numerical study on the interaction of the non-simulated deterioration modes of the columns of non-ductile RC frames to determine their final capacity. The structural behavior of the analyzed frames is described with a model implemented in OpenSEES code [McKenna et al. 2000] accounting for flexure, shear and axial deterioration modes. The developed model is numerically efficient, thus being suitable for everyday use. 
In this work, two benchmark buildings are analyzed with the developed model:

- Van Nuys Hotel. This RC building was designed without any seismic provision and is commonly considered as a test-bed case, thus having been studied by several researchers. In this work, pushover analyses and IDA are carried out with the developed model and with more simplified ones, representing those that are commonly employed in earthquake engineering. The objective of these analyses is to study the relevance of the hidden deterioration modes. Results from the pushover analyses show that the hidden modes that are not detected by the abridged models play a relevant role in the global seismic behavior, affecting the building seismic capacity significantly.

- Prototype building. A prototype building designed only for gravity loads [Bracci et al. 1995] is also analyzed. Pushover analyses and IDA are performed; the obtained results corroborate the observations from the Van Nuys building. As well, the developed model is validated with experimental results on a one-third scale laboratory model of the prototype building.

The results for both buildings confirm that the simplified models grossly overestimate the building capacity; conversely, the developed model detects the hidden deterioration modes whereas having a moderate computational cost.

Developed model

Background

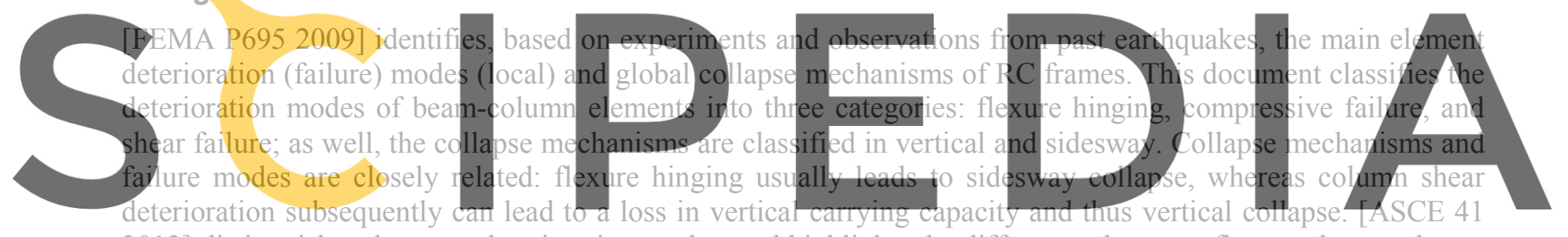

2013] distinguishes the same deterioration modes, and highlights the differences between flexure-shear and pure

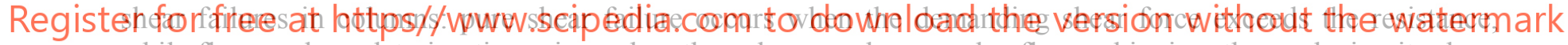
while flexure-shear deterioration arises when the column undergoes also flexure hinging, thus reducing its shear strength. Modeling flexure-shear deterioration is a complex task due to the interaction of moment, shear, and axial forces; several displacement-based models have been proposed: [Pujol et al. 1999; Kato, Ohnishi 2001; Elwood 2004]. [Elwood 2004] uses zero-length shear and axial springs that are connected in series with the column. Elwood model succeeds in capturing the aforementioned failure modes and has been verified and recommended by several studies and standards [Yavari et al. 2008; FEMA P695 2009; ATC 78-1 2015].

Several researchers have studied the consequences of disregarding the deterioration modes other than flexure hinging. In these studies, failure modes other than flexure are detected at the post-processing stage. Conversely, in this paper, that detection is made during the analysis. The interaction between these modes is captured, and different collapse mechanisms are identified. In [Haselton and Deierlein 2007], probabilistic formulations are used to describe the capacity of the structure. [Aslani, Miranda 2005] developed fragility functions based on 92 cyclic tests of RC columns; these functions detect column shear and axial failure by post-processing the results from ordinary dynamic analyses. In [Aslani, Miranda 2005], columns yielded first in flexure prior failing in shear, this being the so-called "flexure-shear" deterioration mode. Aslani and Miranda defined four damage states: (1) light cracking, (2) severe cracking, (3) shear deterioration and (4) loss of load-carrying capacity; the proposed fragility functions predict the probability of each damage state in terms of drift ratio, axial load ratio and transverse reinforcement amount. The research by Aslani and Miranda shows that the proposed fragility functions provide improved probability estimates. This formulation is recommended in [Haselton, Deierlein 2007; Liel 2008; Haselton et al. 2009]. [Liel 2008] carried out IDAs of an 8-story RC frame using the fragility functions developed by Aslani and Miranda. Results in [Liel 2008] showed that, for some records, the shear and axial deterioration modes govern the collapse; noticeably, for some non-ductile structures, the collapse probability increases by $30 \%$ after taking into consideration those same modes. 


\section{General description}

The developed model stems from the researches described in the previous subsection. It accounts for flexure hinging in beams and for 4 deterioration modes in columns: (i) flexure hinging, (ii) flexure-shear, (iii) flexureshear-axial, and (iv) compressive. After flexure hinging, flexure-shear consists in a shear failure of concrete, and yielding or fracture in the transverse reinforcement, while there is still some axial carrying capacity; flexureshear-axial failure represents the total loss of axial capacity. Finally, compressive failure is characterized by concrete crushing, longitudinal reinforcement buckling, and transverse reinforcement yielding or rupture. In the developed model, flexure hinging and compressive failure are described with distributed plasticity (fiber models); flexure-shear and flexure-shear-axial are simulated with shear and axial springs, respectively. Pure shear failure (shear strength) is not explicitly incorporated in the analysis because, when such failure occurs, the structure is severely damaged and is at serious risk of collapse. In this case, the continuation of the analysis is of little interest, as this state can be considered itself as collapse; hence, this verification is carried out during postprocessing. Other hidden deterioration modes in the beam-column joints (flexure, shear and lap splice failure [Aycardi et al. 1994, Jeon et al. 2015; De Risis et al. 2017]) are not considered in this model.

The frame elements are discretized with Navier-Bernouilli beam-column elements, as depicted in Fig. 1.

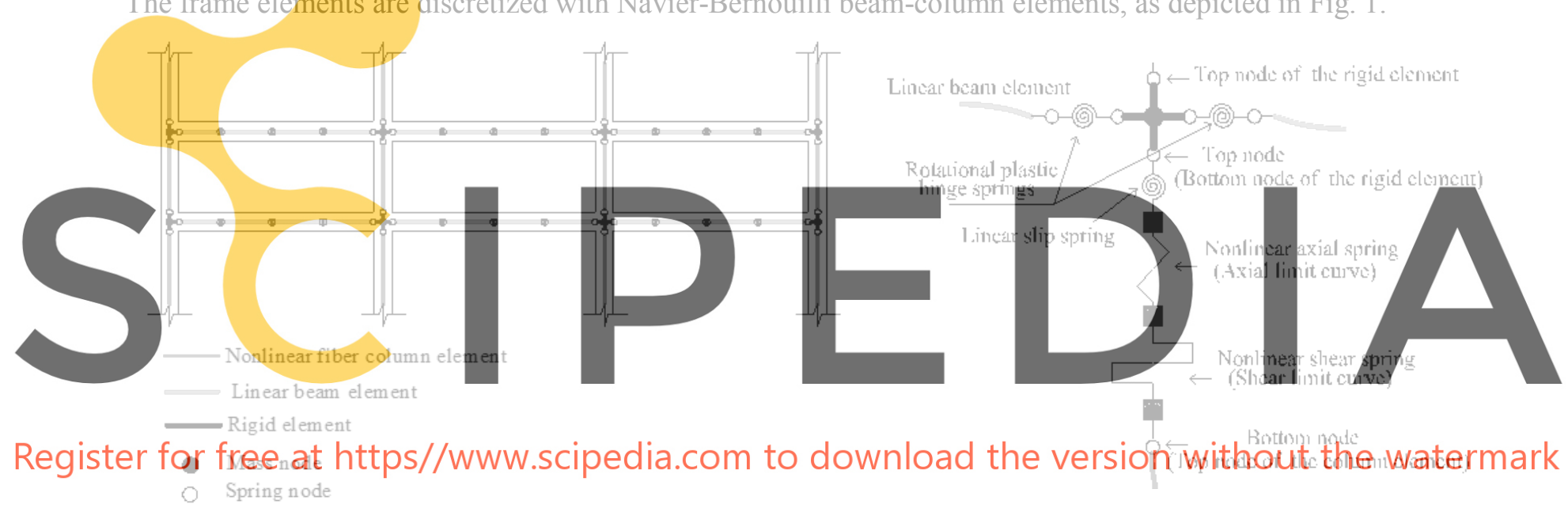

(a) Frame discretization

(b) Detail of the discretization of a beam-column joint

Fig. 1. Developed model

Fig. 1.a and Fig. 1.b display examples of the discretization of a frame and a beam-column joint, respectively. The beams nonlinear behavior is described with concentrated plasticity while columns are analyzed with distributed plasticity fiber models; therefore, the main segments of beams exhibit linear behavior, and those of columns behave nonlinearly. Fig. 1.a shows that additional nodes are used to account for the higher stiffness of the beam-column joints; namely, mass nodes are located at the intersection points, and spring nodes are situated at the joints ends. Also, additional spring nodes are set at intermediate sections inside the beams. Fig. 1.b shows that, in beams, flexure hinging is modelled with zero-length rotational springs (concentrated plasticity); conversely, in columns, similar springs are used to describe the longitudinal reinforcement slip. As discussed previously, the shear and axial springs in columns represent the flexure-shear and flexure-shear-axial failures, respectively.

This model is implemented in OpenSEES code [McKenna et al. 2000]; the drift capacity model developed in [Elwood 2004] is used to describe the flexure-shear and flexure-shear-axial deterioration of columns. The second order effects are accounted for by P-delta analysis. The consideration of beams and columns nonlinear behavior is described next.

Beams. The rotational springs behavior is described with the modified hysteretic model developed by [Ibarra et al. 2005]. The particular parameters of the [Ibarra et al. 2005] model are obtained from the sectional analysis of 
the beams; other parameters, such as the plastic rotations and the energy dissipation, are selected after the formulations proposed by [Haselton et al. 2008].

Columns. The fiber models are implemented using the force-based formulation. The integration along the column length is carried out by the Gauss-Lobatto quadrature rule with five integration points. The concrete uniaxial behavior is represented by the "Concrete01" model with zero tensile strength; in compression, there is a parabolic segment followed by a linear descending branch. The concrete confinement is taken into consideration according to [Scott et al. 1982]. The reinforcement behavior is simulated with the "Steel 02" model.

\section{Bond-slip effects in columns}

The longitudinal reinforcement slip at the column ends is represented by an increase in the corresponding rotation angles. As discussed previously, this effect is simulated by zero-length rotational springs, see Fig. 1.b. The spring stiffness is selected as recommended by [Elwood, Eberhard 2009]:

$$
C_{\text {slip }}=\frac{8 f_{\mathrm{b}}}{d_{\mathrm{b}} f_{\mathrm{s}}} E I_{\mathrm{flex}}
$$

In equation (1), $C_{\text {slip }}$ is the rotational stiffness of the slip spring, $d_{b}$ is the bar nominal diameter, $E I_{\text {flex }}$ is the column effective flexure rigidity at the first yield, $f_{s}$ can be taken equal to the yield stress $f_{\mathrm{y}}$ [Berry et al. 2004], and $f_{\mathrm{b}}$ is the bond stress given by $0.8 \sqrt{f^{\prime}}{ }_{\mathrm{c}}(\mathrm{MPa})$ [Yavari et al. 2008]. Equation (1) corresponds to linear behavior; after reinforcement yielding, the behavior can be significantly nonlinear and may lead to rapid strength reduction. The authors have developed a more complex model [Alfarah et al. 2017] that is able to reproduce the
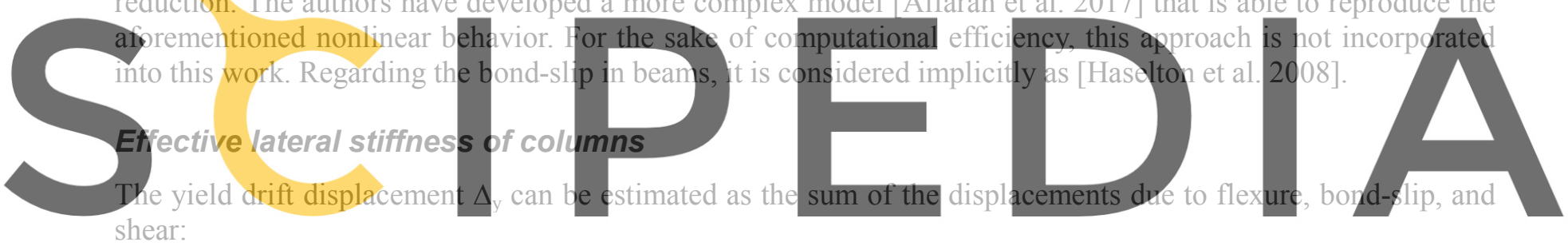

Register for free at https//www.scipedia.eont teliq dwanlaad the version without the watermark

The displacements in the right-hand side of equation (2) can be estimated [Elwood, Eberhard 2009] as:

$$
\Delta_{\text {flex }}=\frac{L^{2}}{6} \phi_{\mathrm{y}}=\frac{L^{2}}{6} \frac{M_{\mathrm{SP}}}{E I_{\mathrm{flex}}} \quad \Delta_{\text {slip }}=\frac{L d_{\mathrm{b}} f_{\mathrm{s}} \phi_{y}}{8 f_{\mathrm{b}}} \quad \Delta_{\text {shear }}=\frac{2 M_{\mathrm{SP}}}{G A_{\mathrm{eff}}}
$$

In equation (3), $L$ is the column length, $\phi_{\mathrm{y}}$ is the yield curvature, $M_{\mathrm{SP}}$ is the moment at concrete spalling, and $E I_{\text {flex }}$ and $G A_{\text {eff }}$ are the effective flexure and shear stiffness, respectively. The flexure displacement $\Delta_{\text {flex }}$ is obtained assuming that the column is clamped at both ends, and that the curvature varies linearly along its height, being zero at the mid-section. $M_{\mathrm{SP}}$ corresponds to concrete strain equal to 0.004 ; it includes the effects of axial gravity loads. $E I_{\text {flex }}$ can be determined from the moment and the curvature at the first yield. Finally, $E I_{\text {eff }}$ is expressed as:

$$
E I_{\mathrm{eff}}=\frac{L^{2}}{6} \frac{M_{\mathrm{SP}}}{\Delta_{\mathrm{y}}}
$$

This stiffness is used in the idealized bilinear model for the shear displacement law described in next subsection. Since this model assumes that the flexure failure will precede the shear one, equation (2) can be considered as a good approximated statement to add the influence of the different components of displacement at the flexural yielding state.

\section{Flexure-shear and flexure-shear-axial deterioration models of columns}

Several studies [Priestley et al. 1994; Sezen 2002] have shown that, when the inelastic deformation increases, the shear strength decays; hence, the flexure-shear deterioration model should be based on both force and deformation. Also, after the flexure-shear degradation, the columns tend to lose their vertical carrying capacity [Nakamura and Yoshimura 2002]. In this work, flexure-shear and flexure-shear-axial deterioration are described 
with shear and axial limit curves respectively [Elwood 2004], respectively; such curves refer to the corresponding shear and axial springs that are series connected with the column fiber elements, see Fig. 1.b.

The aforementioned shear spring predicts deterioration according to an empirical drift function [Elwood, Moehle 2006] that is based on experimental results; later, axial deterioration arises from sliding along an inclined shear crack. The following equations provide the drift limit angle at flexure-shear $\left(\Delta_{\mathrm{s}} / L\right)$ and flexure-shear-axial $\left(\Delta_{\mathrm{a}} /\right.$ $L$ ) deteriorations, respectively:

$$
\frac{\Delta_{\mathrm{s}}}{L}=\frac{3}{100}+4 \rho^{\prime \prime}-\frac{1}{40} \frac{v}{\sqrt{f^{\prime}{ }_{\mathrm{c}}}}-\frac{1}{40} \frac{P}{A_{g}{f^{\prime}}_{\mathrm{c}}} \geq \frac{1}{100} \quad \frac{\Delta_{\mathrm{a}}}{L}=\frac{4}{100} \frac{1+\tan ^{2} \theta}{\tan \theta+P \frac{S}{A_{\mathrm{st}} f_{\mathrm{yt}} d_{\mathrm{c}} \tan \theta}}
$$

In equation (5), $\rho^{\prime \prime}$ is the transverse reinforcement ratio, $v$ is the demanding shear stress $\left(V / A_{\mathrm{g}}\right), P / A_{\mathrm{g}} f_{\mathrm{c}}^{\prime}$ is the demanding axial load ratio, $d_{\mathrm{c}}$ is the column core depth (between centre lines of stirrups), $S$ is the transverse reinforcement spacing, $A_{\text {st }}$ and $f_{\mathrm{yt}}$ are the area and the yield point of the transverse reinforcement, and $\theta$ is the critical crack angle $\left(\theta=65^{\circ}\right.$, [Elwood, Moehle 2006]). Units are in $\mathrm{MPa}$.

When the response reaches the shear limit curve $\left(\Delta_{\mathrm{s}} / L\right.$ in equation (5)), the backbone curve of the shear spring is shifted to a descending branch [Elwood 2004]. Then, the total lateral stiffness is obtained by combining the negative slope of this descending branch with the positive one given by equation (4). The slope of the postfailure backbone of the shear spring is $K_{\mathrm{deg}}=\left[1 / K_{\mathrm{deg}}{ }^{\mathrm{t}}-1 / K_{\text {unload }}{ }^{-1}\right.$ [Elwood 2004]. In this expression, $K_{\mathrm{deg}}{ }^{\mathrm{t}}$ is the softening slope of the total response and $K_{\text {unload }}$ is the column unloading stiffness; $K_{\text {unload }}=12 E I_{\text {eff }} / L^{3}$ where $E I_{\text {eff }}$ is obtained from equation (4). The initial stiffness of the shear spring is equal to the uncracked column shear

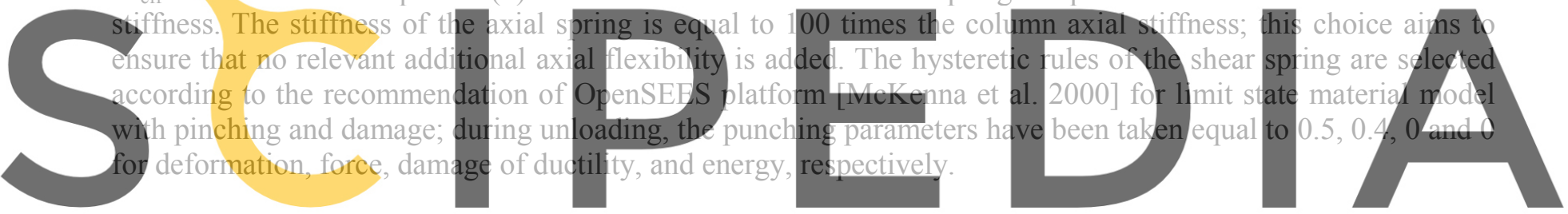

Numerical integration

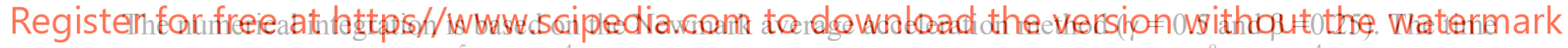
step ranges between $2 \times 10^{-5}$ and $10^{-4} \mathrm{~s}$; in the iterations, the tolerance ranges between $10^{-8}$ and $10^{-4}$.

\section{Final considerations}

It should be emphasized that this paper is not actually proposing a new model, instead it presents a new combination of approaches that had been previously developed by other researchers. The interest of this combination lies in putting together sufficient accuracy and computational efficiency. Although other combinations have been previously proposed, some of them either consider older formulations to describe beams hinges [Elwood, Moehle 2003], or are less computationally efficient [Baradaran Shoraka et al. 2013a, 2013b], or do not account for all the columns failure modes [Jeon et al. 2015].

\section{Models considered in the analyses}

To highlight the importance of the hidden failure modes of columns (flexure-shear deterioration followed by loss of bearing capacity), the results provided by four models are compared in this paper. These models are implemented in OpenSEES following the approach described in the previous subsections; differ in their complexity and the number of deterioration modes that are taken into consideration:

- Model 1. Corresponds to the simple algorithms that are commonly used in earthquake engineering. The material degradation in beams and columns is simulated through concentrated and distributed plasticity, respectively. The second-order effects are described by P-delta analysis, as discussed previously. The bond slip in columns is analyzed with the simplified formulation in equation (1). This model is able to detect only the sidesway collapse.

- Model 2. Akin to Model 1, although without second-order analysis. 
- Model 3. This model is analogous to the first one, but considers also the flexure-shear deterioration by attaching a shear spring in series with a bond slip element at each column top (Fig. 1.b).

- Model 4. This model is generated, following Model 3, by incorporating also axial springs (Fig. 1.b). For the sake of better numerical stability, these springs are incorporated only to columns that have experienced flexure-shear deterioration. In contrast to the previous models, this one is able to predict both sidesway and vertical collapses.

\section{Van Nuys Hotel Building}

The Van Nuys Hotel is considered by the Pacific Earthquake Engineering Research Center (PEER) as a test-bed structure. As a result, this construction has been studied by several researchers [Krawinkler 2005] and had been instrumented prior to the 1994 Northridge earthquake. This building has a non-ductile 7-story RC framed structure without basements, and its plan configuration is rectangular $(19.20 \mathrm{~m} \times 45.72 \mathrm{~m})$, being uniform along the building height [Vamvatsikos et al. 2003]. The Van Nuys building is located in San Fernando Valley, California, having been built in 1966 and having experienced several significant earthquakes; suffered minor structural damage and extensive non-structural damage during the 1971 San Fernando earthquake, and extensive structural damage during the 1994 Northridge earthquake. In this work, the seismic performance of the building is analyzed in the short direction; the structure is represented by a 2D façade frame. In the beams, only flexural hinging is expected; in the columns, also flexural-shear possibly followed by flexural-shear-axial failure are anticipated.

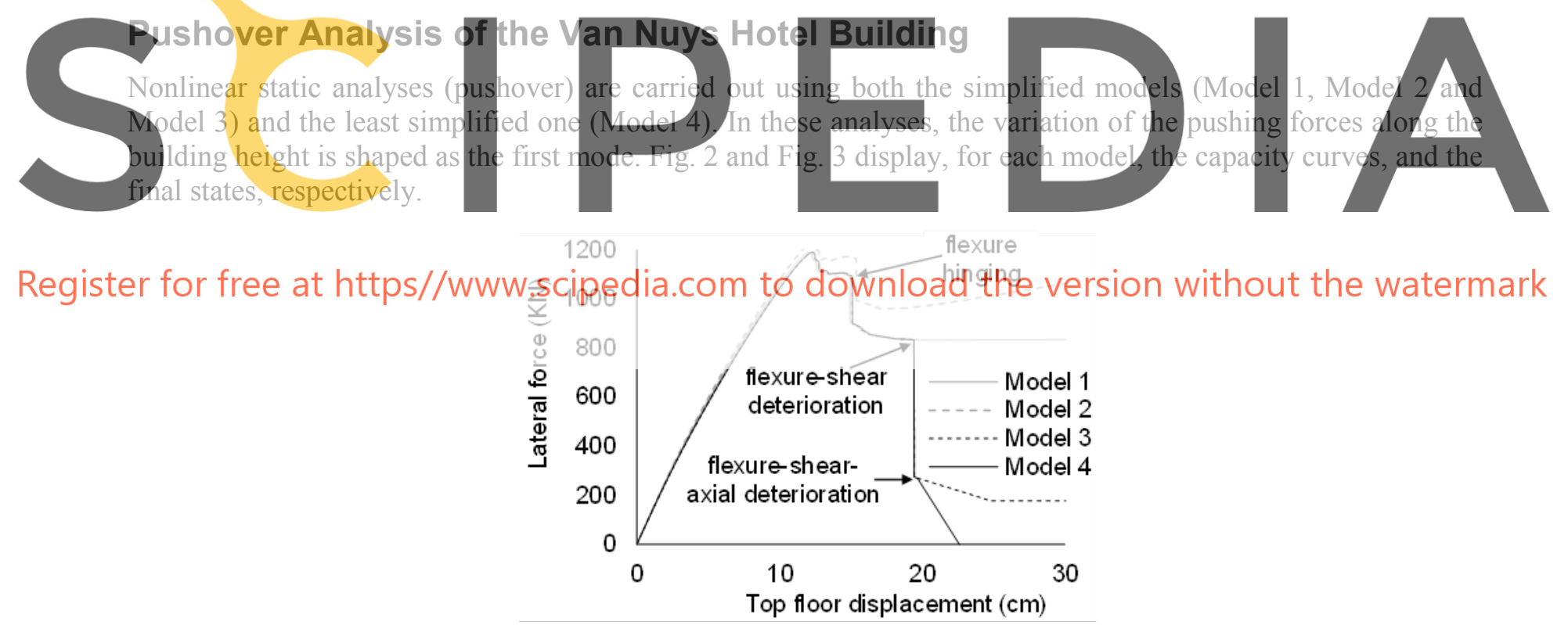

Fig. 2. Capacity curve of the Van Nuys frame for the four models

Fig. 2 shows that, before reaching the maximum force capacity, the four models predict almost the same behavior; the slight difference for Model 2 can be explained by the influence of the second-order effects. After this peak, all the models describe flexure hinging degradation, followed by a near horizontal branch, with highly similar results for Models 1, 3 and 4. When flexure-shear deterioration is detected by Models 1 and 4, a brittle vertically descending branch is generated. When this branch reaches the residual strength, axial deterioration is identified by Model 4 and a linear descending branch begins, leading finally to zero-force state. As expected, Fig. 2 shows that, the more deterioration modes are accounted for, the less residual (post-peak) capacity is predicted; in other words, using over-simplified models is significantly non-conservative. 


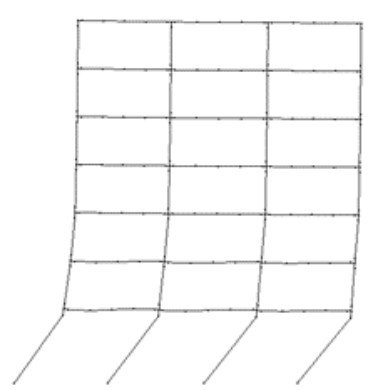

(a) Model 1

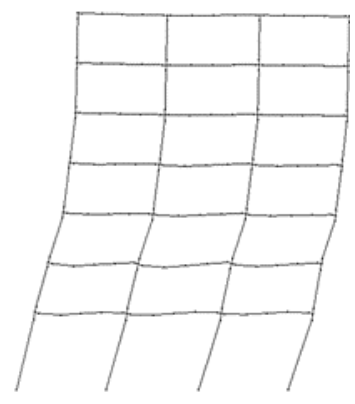

(b) Model 2

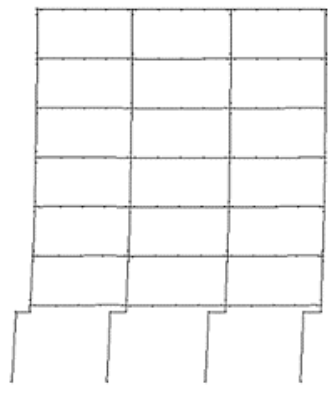

(c) Model 3

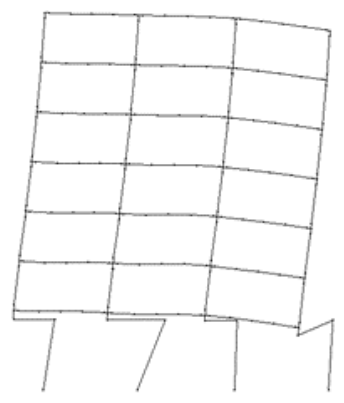

(d) Model 4

Fig. 3. Collapse deformation of the Van Nuys frame in the pushover analyses

Fig. 3.a through Fig. 3.d represent the collapse mechanisms detected by Models 1 through 4, respectively. Models 1 and 2 predict sidesway mechanisms. Model 1 indicates that the plastic hinges are concentrated on the first-floor; conversely, Model 2 states that hinging is distributed among the columns of first through fifth stories. Fig. 3.c shows that flexure-shear deterioration arises in the first-floor columns tops; this is mainly due to their low capacity caused by their large height, thus generating brittle collapse mechanisms. Fig. 3.d represents the onset of the vertical capacity loss in the right column (C36) due to relevant flexure-shear-axial deterioration; subsequent larger deformation states cannot be captured due to non-convergence. However, this state can be

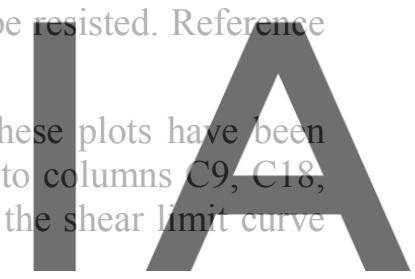

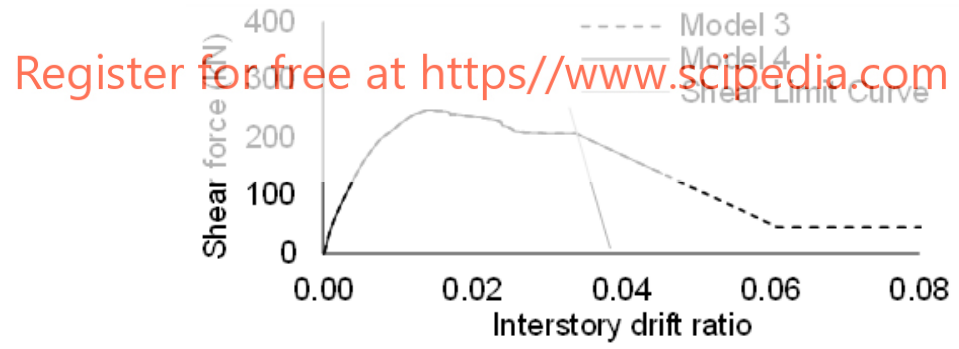

(a) Column C9 (left column in Fig. 3)

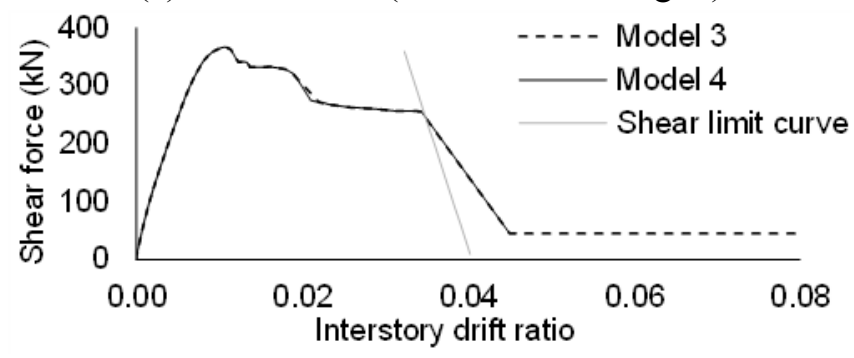

(c) Column C27 (third column in Fig. 3)

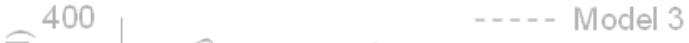

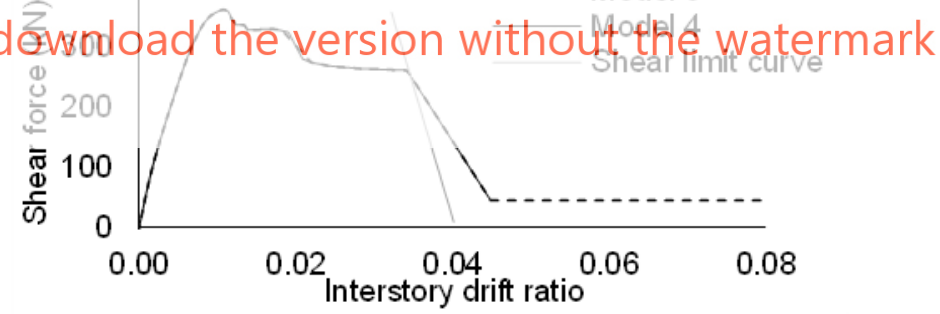

(b) Column $\mathrm{C} 18$ (second column in Fig. 3)

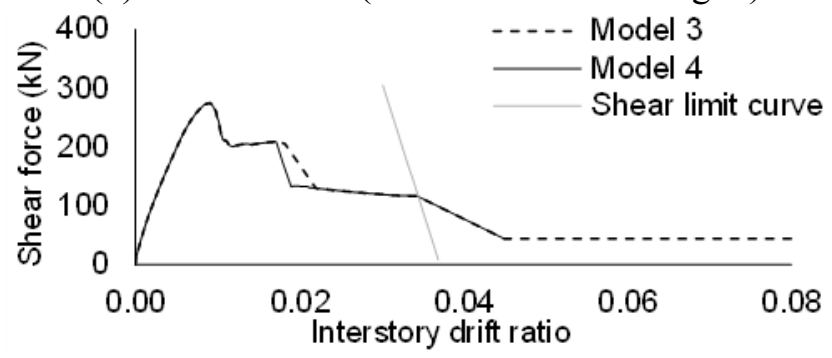

(d) Column C36 (right column in Fig. 3)

Fig. 4. Shear force vs. story drift for the first-floor columns of the Van Nuys frame in the pushover analysis with Models 3 and 4

$\left(\Delta_{\mathrm{s}} / L\right.$ in equation (5)), the response degrades until reaching a certain residual strength. 
Fig. 4 shows that the flexural-shear failure is detected while columns exhibit softening in their forcedisplacement response. This circumstance requires particular discussion, since it is recommended that the response maintains a positive slope to ensure a unique solution in the Elwood model [Elwood 2004]. If that slope is negative, there are three solutions satisfying equilibrium and ensuring a total drift increase. Among them, the correct one corresponds to damage localized in the shear spring, and unloading shear-drift response [Elwood 2004]. To fulfill these requirements, the shear force shall decrease faster than before reaching the shear limit curve. The proof that the solution is correct is that the shear response from Model 3 decreases linearly until reaching the shear spring residual strength; this guarantees that the damage is localized in the shear spring. After this limit, the column capacity remains constant; that residual strength is taken equal to $10 \%$ of the maximum shear capacity. However, for cyclic loading, such verification can be made by checking the response of the shear spring; if it does not show shear degradation upon reaching the shear limit curve, it is recommended to modify the time increment and the convergence parameters until this condition is satisfied.

Fig. 5 displays plots of the axial force vs, the interstory drift ratio for the most loaded column (right, C36). Fig. 5 shows that, as highlighted by Fig. 3.d, the limit axial curve is reached after the flexure-shear deterioration.

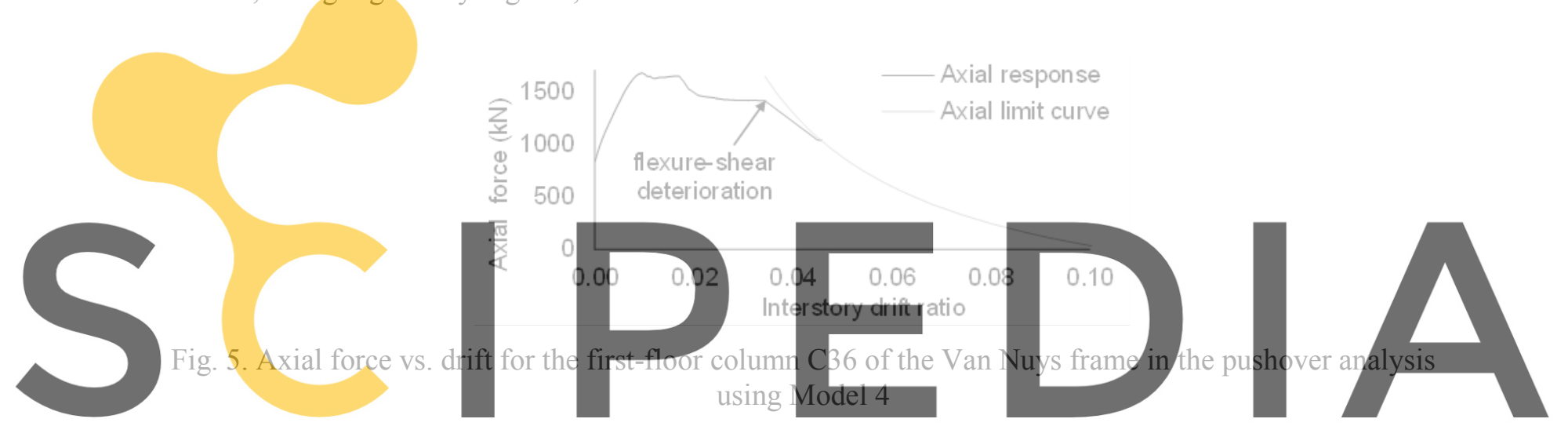

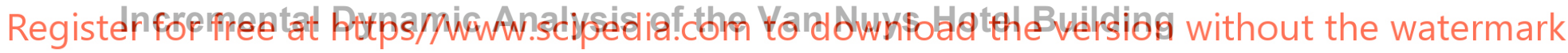

An Incremental Dynamic Analysis (IDA) is carried out for the 1979 Imperial Valley ground motion, Plaster City station record. The first mode period is taken as $1.3 \mathrm{~s}$; the $5 \%$ damping spectral ordinate for the unscaled record is $S_{\mathrm{a}}(1.3)=0.244 \mathrm{~g}$. Models 1 and 4 are considered. In Model 1, Rayleigh damping being proportional to mass and initial stiffness is used; the damping ratio is $5 \%$ at the first and second modes. In Model 4, mass-proportional damping (5\%) is considered; noticeably, stiffness-proportional damping cannot be used due to the unrealistically large damping forces resulted from the sudden shear and axial deterioration of the zero-length springs [Elwood, Moehle 2003]. In the most critical analyses, the time step is $0.00002 \mathrm{~s}$.

Fig. 6 displays IDA curves in terms of the top floor displacement (Fig. 6.a) and the maximum interstory drift ratio (Fig. 6.b) vs. the spectral acceleration at the building fundamental period $\left(S_{\mathrm{a}}\left(T_{1}\right)\right)$ ) Fig. 6.a shows that Model 1 predicts higher capacity than the more sophisticated Model 4. Regarding Model 3, the large peak displacement that corresponds approximately to spectral acceleration $0.5 \mathrm{~g}$ can be read as collapse; therefore, the segment for higher accelerations can be considered as a structural resurrection, being only of academic interest. Fig. 6.b provides basically the same conclusions than Fig. 6.a, although the maximum drift yields information on the behavior along the building height. In short, the oversimplified models grossly overestimate the seismic capacity and generate irregular plots; conversely, the most complex models provide more reliable and smoother IDA curves. Comparison with the IDA curves in [Vamvatsikos et al. 2003] shows similarity with the results for Model 1. 


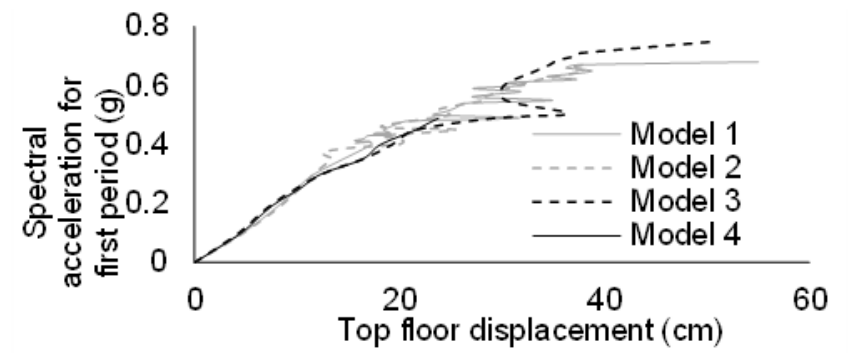

(a) Top story

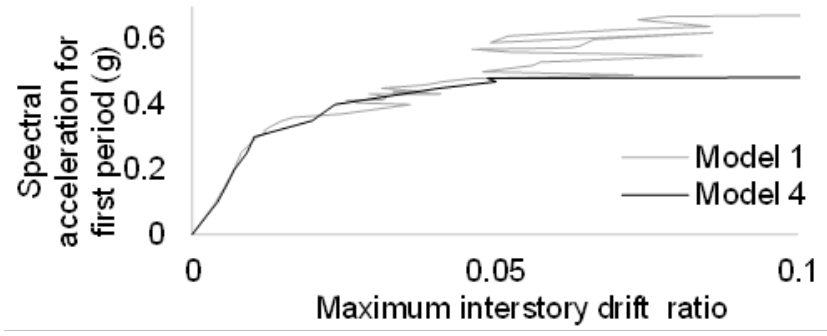

(b) Maximum drift angle

Fig. 6. IDA curves of the Van Nuys frame with the Imperial Valley ground motion

Fig. 6 shows that Model 4 predicts collapse at $S_{\mathrm{a}}\left(T_{1}\right)=0.49 \mathrm{~g}$; that collapse arises by a loss of the axial carrying capacity (flexure-shear-axial deterioration) of the first-floor columns C9, C18, and C27. Fig. 7 presents four consecutive states of this brittle progressive collapse. State 1 (Fig. 7.a) corresponds to flexure-shear deterioration of the left column (C9). States 2 and 3 (Fig. 7.b and Fig. 7.c) also include flexure-shear deterioration of the other columns (C18, C27, and C36). In state 4 (Fig. 7.d), columns C9, C18, and C27 also have lost their bearing capacity; similarly to Fig. 3.d, subsequent states corresponding to larger deformation cannot be captured. However, this state can be considered as vertical collapse, since the IDA curves from Fig. 6 show no further capacity [Alfarah 2017].

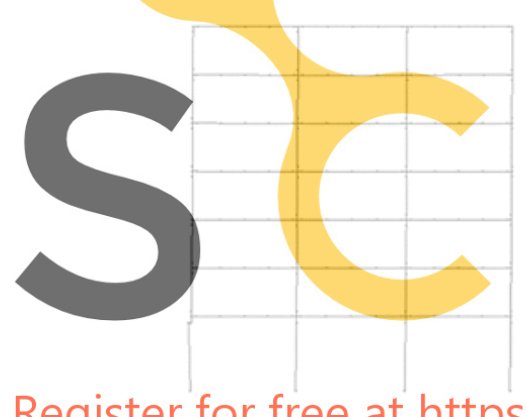

Register for free at https//www.sc

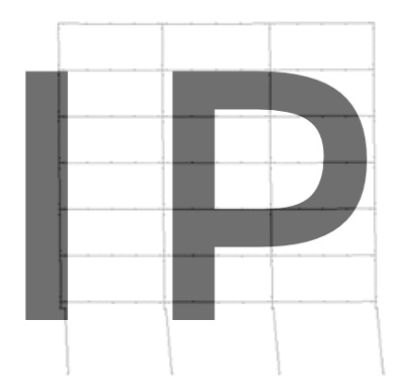

(b) State 2

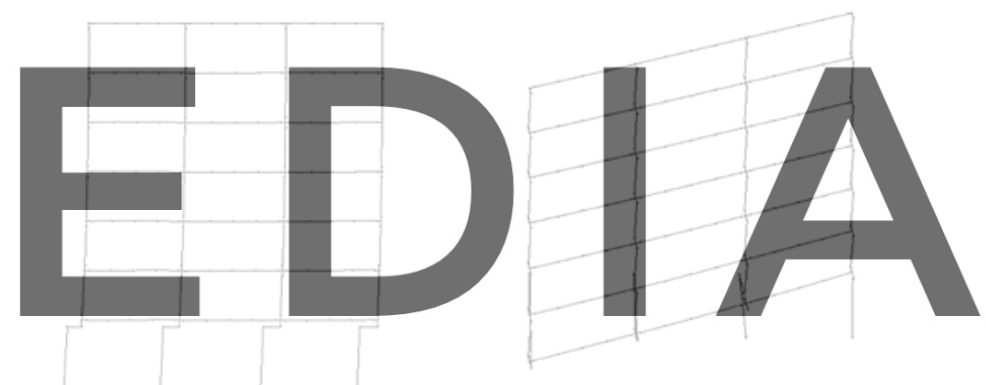
(a) State 1

Fig. 7. Van Nuys frame. Deterioration states. Imperial Valley ground motion. Miodel 4

Among the nonlinear dynamic analyses performed in this IDA, Fig. 8 displays top floor time-histories corresponding to a number of given input intensities. Fig. 8.a and Fig. 8.b contain plots obtained using Models 1 and 4 , respectively.

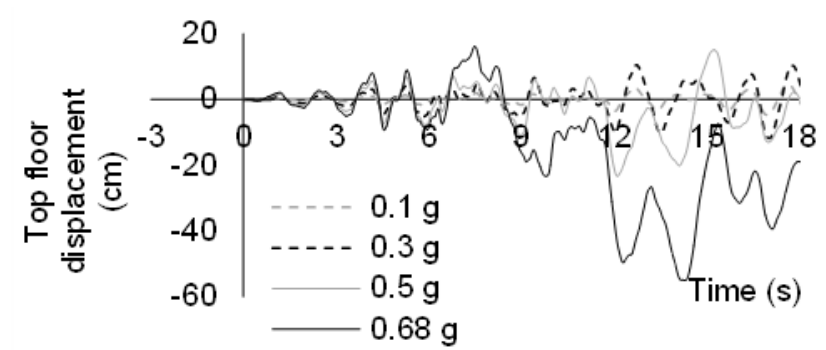

(a) Model 1

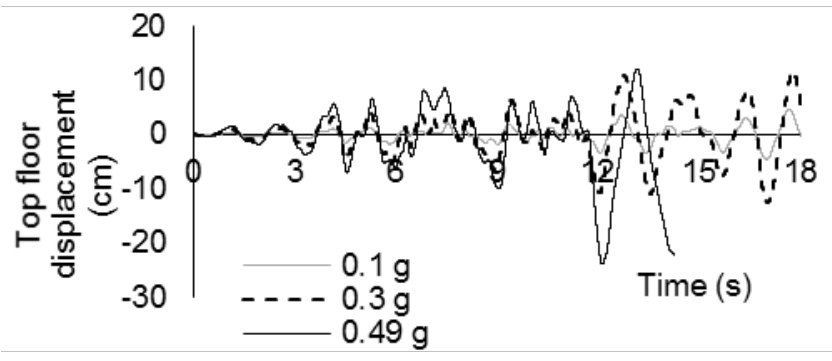

(b) Model 4

Fig. 8. Top floor time histories of the Van Nuys frame with scaled $\left(S_{\mathrm{a}}\left(T_{1}\right)\right)$ Imperial Valley ground motions

Plots from Fig. 8.a show that the response for $S_{\mathrm{a}}\left(T_{1}\right)=0.68 \mathrm{~g}$ is markedly nonlinear, since after $9 \mathrm{~s}$, the average displacement is clearly nonzero; this observation fits Fig. 6.a. Analogously, Fig. 8.b shows that, for Model 4, the response for $S_{\mathrm{a}}\left(T_{1}\right)=0.49 \mathrm{~g}$ reaches the collapse; this circumstance also suits Fig. 6.a. This collapse corresponds to flexural-shear-axial failure, as shown in Fig. 7.d. 
Fig. 9 displays, similarly to Fig. 5, plots of axial force vs. story drift for the first-floor columns; the shown plots correspond to the final time-history analysis using Model 4 (that is, $S_{\mathrm{a}}\left(T_{1}\right)=0.49 \mathrm{~g}$ ). Fig. 9 confirms that columns C9, C18 and C27 reach their axial limit curves; the bigger losses are experienced by columns C9 (mainly) and C18. Noticeably, comparison of the plots in Fig. 9 shows that when a column reaches its axial limit curve, the subsequent axial force reduction is immediately followed by an increase in the other columns axial

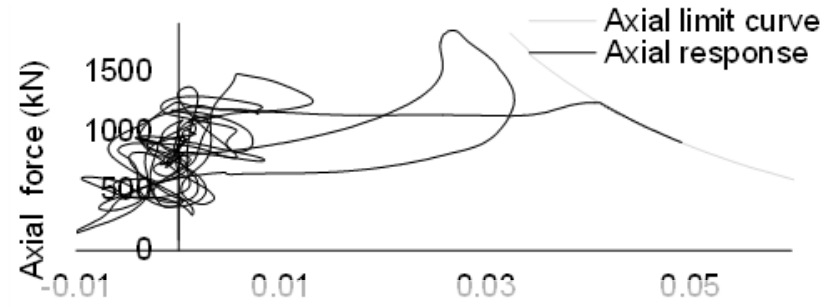

Interstory crift ratio

(a) Column C9 (left column in Fig. 7)

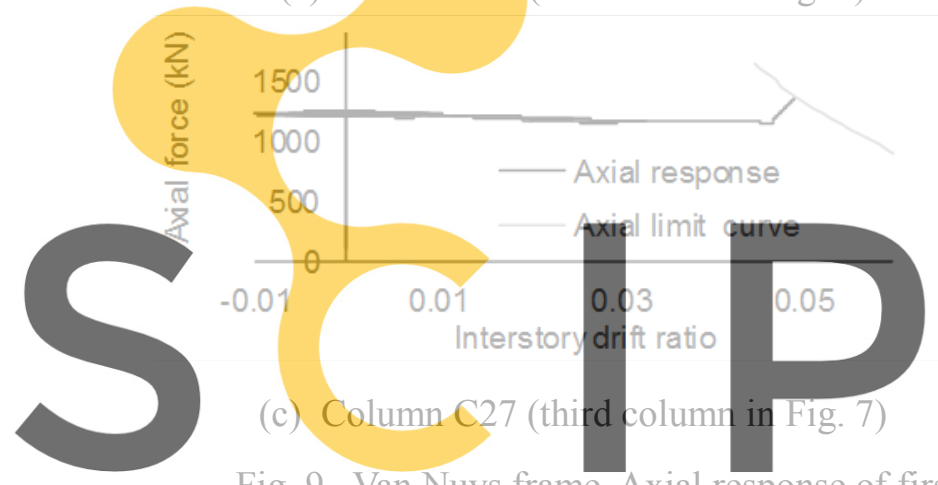

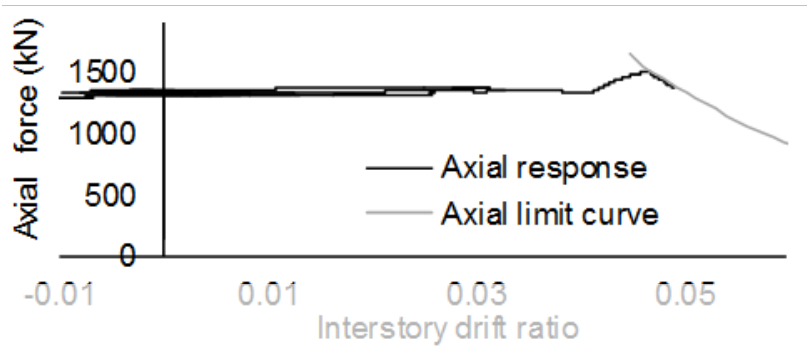

(b) Column C18 (second column in Fig. 7)

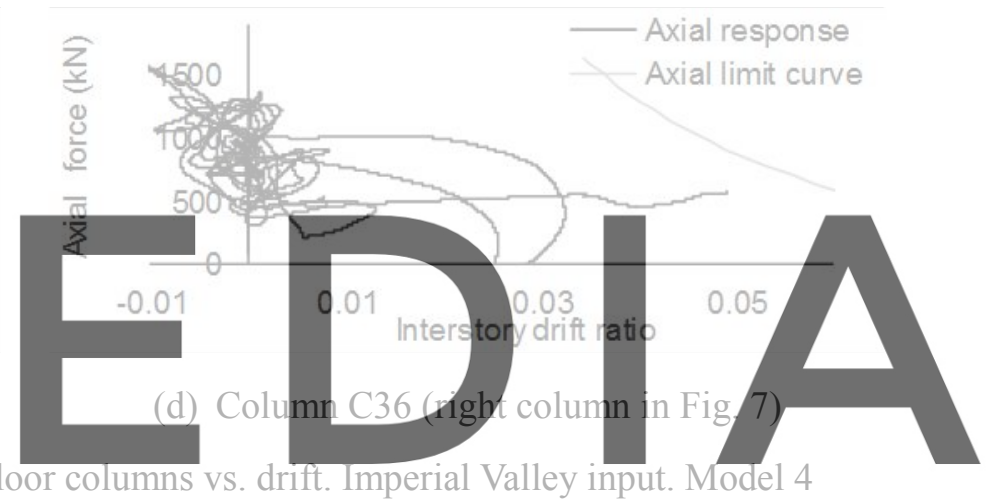

Registeprfos free at https//www.scipedia.com to download the version without the watermark Since the [Elwood 2004] model assumes that flexure-shear and flexure-shear-axial deterioration precedes the shear strength failure, it is necessary to verify that the demanding shear force does not exceed the corresponding capacity. Such capacity is selected according to [ASCE 41 2013], since it allows consideration of the changes of moment shear, and axial forces at each time increment. The inherent conservatism of any design code is mitigated by taking $\phi=1$. Fig. 10 displays, for the same case than Fig. 9, the time histories of the first-floor columns shear force, together with the shear strength $V_{\mathrm{n}}$. Plots from Fig. 10 show that the demanding shear forces do not exceed that strength. Noticeably, the highest variability of $V_{\mathrm{n}}$ in columns 9 and 36 (Fig. 10.a and Fig. 10.d) is due to the bigger oscillation of the demanding axial force, since such columns are located in external positions; as well, the observed spikes correspond to limitations of the moment/shear ratio [ASCE 41

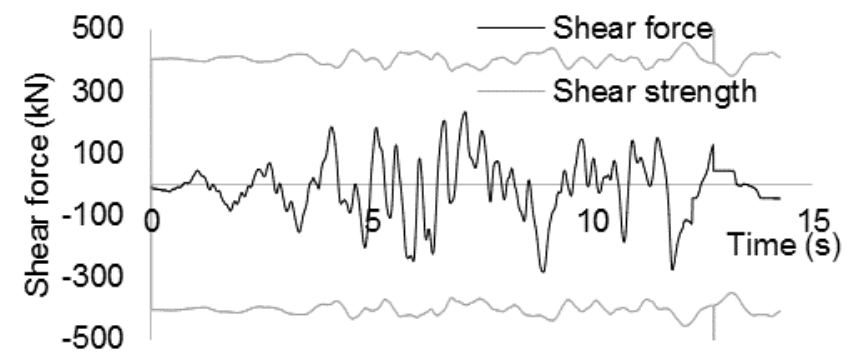

(a) Column C9 (left column in Fig. 7)

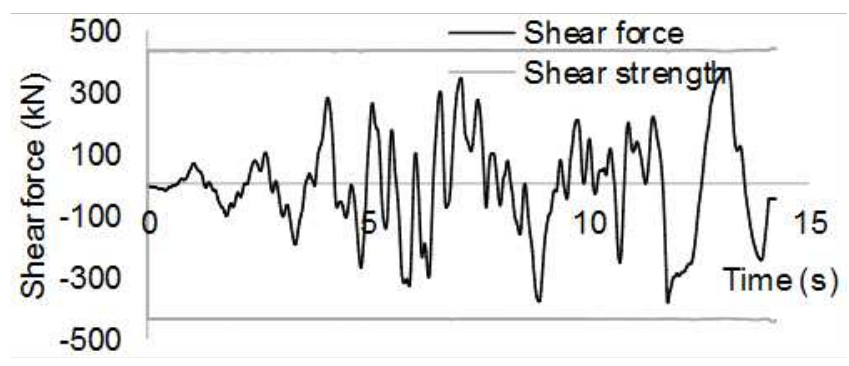

(b) Column C18 (second column in Fig. 7) 2013]. 


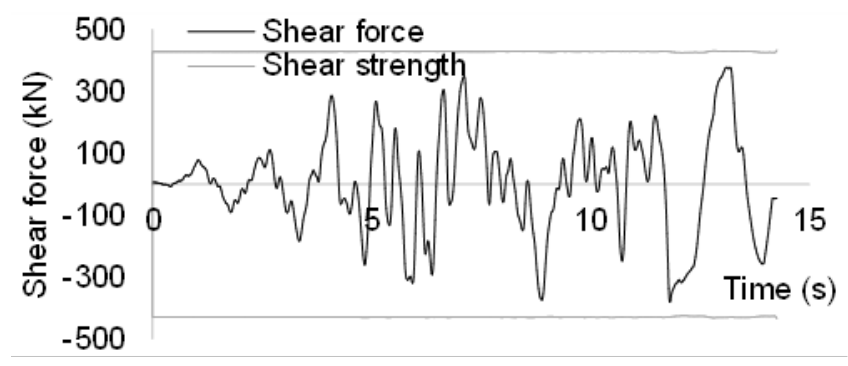

(c) Column C27 (third column in Fig. 7)

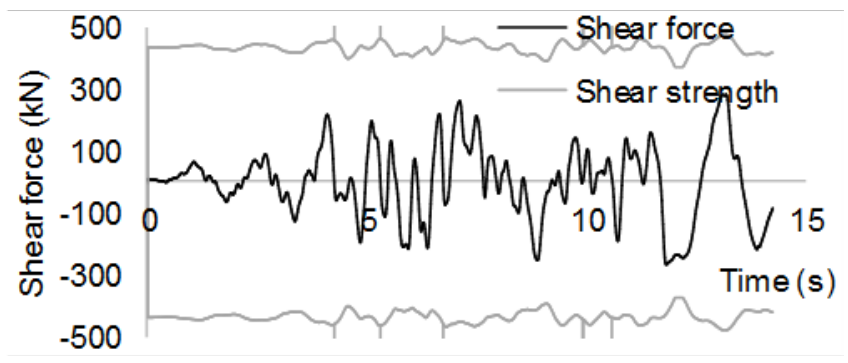

(d) Column C36 (right column in Fig. 7)

Fig. 10. Van Nuys frame. Shear force history of first-floor columns. Imp. Valley scaled to $\mathrm{S}_{\mathrm{a}}\left(T_{1}\right)=0.49 \mathrm{~g}$. Model 4

After Fig. 10, Fig. 11 displays a zoom view of the time histories of columns C9 and C36 in the latest time interval. Plots from Fig. 11 show that, prior to the flexure-shear deterioration of column C9, both histories are similar; then, that failure generates a relevant reduction in the shear force of column $\mathrm{C} 9$ and an equivalent increase in column C36. Later, the flexure-shear-axial deterioration of column C9 arises $(t=14.10 \mathrm{~s})$ after having reached its residual shear strength.

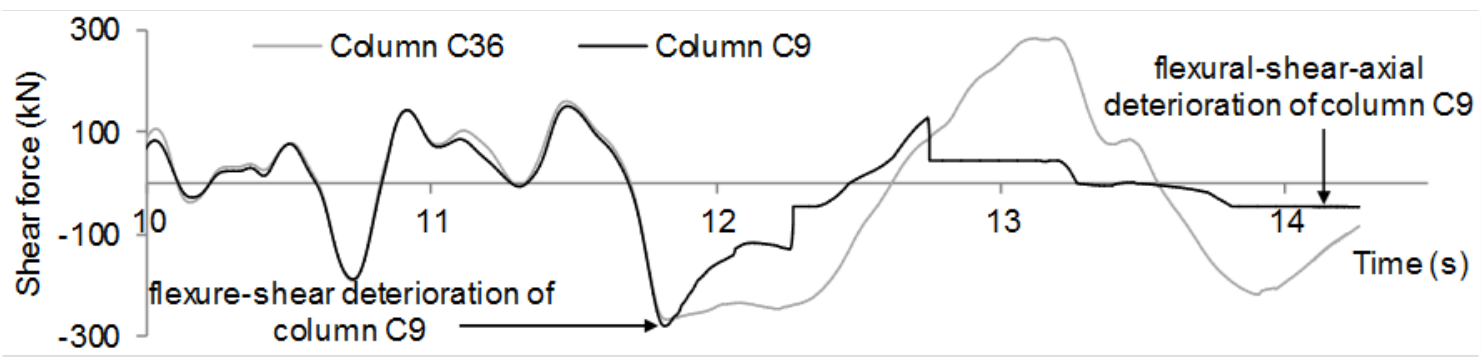

Fig. 11. Van Nuys frame. Shear force time histories of columns C9 and C36. Imperial Valley scaled to $\mathrm{S}_{\mathrm{a}}\left(T_{1}\right)$ $=0.49 \mathrm{~g}$. Model 4

\section{Prototype Building}

This section describes a 3-story RC framed prototype building that had been intentionally designed only for gravity loads [Bracci et al. 1995]. Other researchers [Jeon et al. 2012] have also studied this building. The floor plan is rectangular $(12.19 \mathrm{~m} \times 23.16 \mathrm{~m}$, with 3 and 4 bays in the short and long directions, respectively) and the story height is $3.66 \mathrm{~m}$. The structure consists of $30.5 \mathrm{~cm} \times 30.5 \mathrm{~cm}$ columns, $23 \mathrm{~cm} \times 46 \mathrm{~cm}$ beams and 15.24 $\mathrm{cm}$ deep two-way solid slabs. The concrete strength is $f_{\mathrm{c}}$ ' $=24 \mathrm{MPa}$ and the steel yield point is $275 \mathrm{MPa}$. A deeper description of the structure can be found in [Bracci et al. 1995]. Noticeably, the column section and the transverse reinforcement amount are small. A one-third scale laboratory model of a part of the prototype building has been tested on a shaking table [Bracci et al. 1995]. The same failure modes as the Van Nuys Building are to be expected.

To investigate the importance of the hidden failure modes, IDA studies on the prototype building are conducted with the developed model. Moreover, to verify the reliability of the derived conclusions, the model is validated next with the aforementioned experimental results.

\section{Numerical simulation of tests on a one-third scale model of the Prototype Building}

This section describes the numerical simulation, using Model 4, of the aforementioned experiments on a reduced-scale laboratory model of the prototype building [Bracci et al. 1995]. These proofs consist in uniaxial shaking table testing of a one-third scale model representing a 3D frame of an internal bay in the short direction 
of the prototype building. The input is a scaled version of the N21E component of the Taft input; after scaling, its PGA is $0.2 \mathrm{~g}$. For the sake of constant acceleration similitude [Bracci et al. 1995], the time of the input signal is reduced with a scale factor $1 /(3)^{1 / 2}$. In the numerical simulation, a mass-proportional $2 \%$ Rayleigh model represents the damping; the time step is $0.01 \mathrm{~s}$.

Neither flexure-shear nor flexure-shear-axial failure are detected in the analysis; this result matches the observed damage [Bracci et al. 1995]. Fig. 12 displays a comparison between the numerical and experimental time histories of the top floor relative displacement.

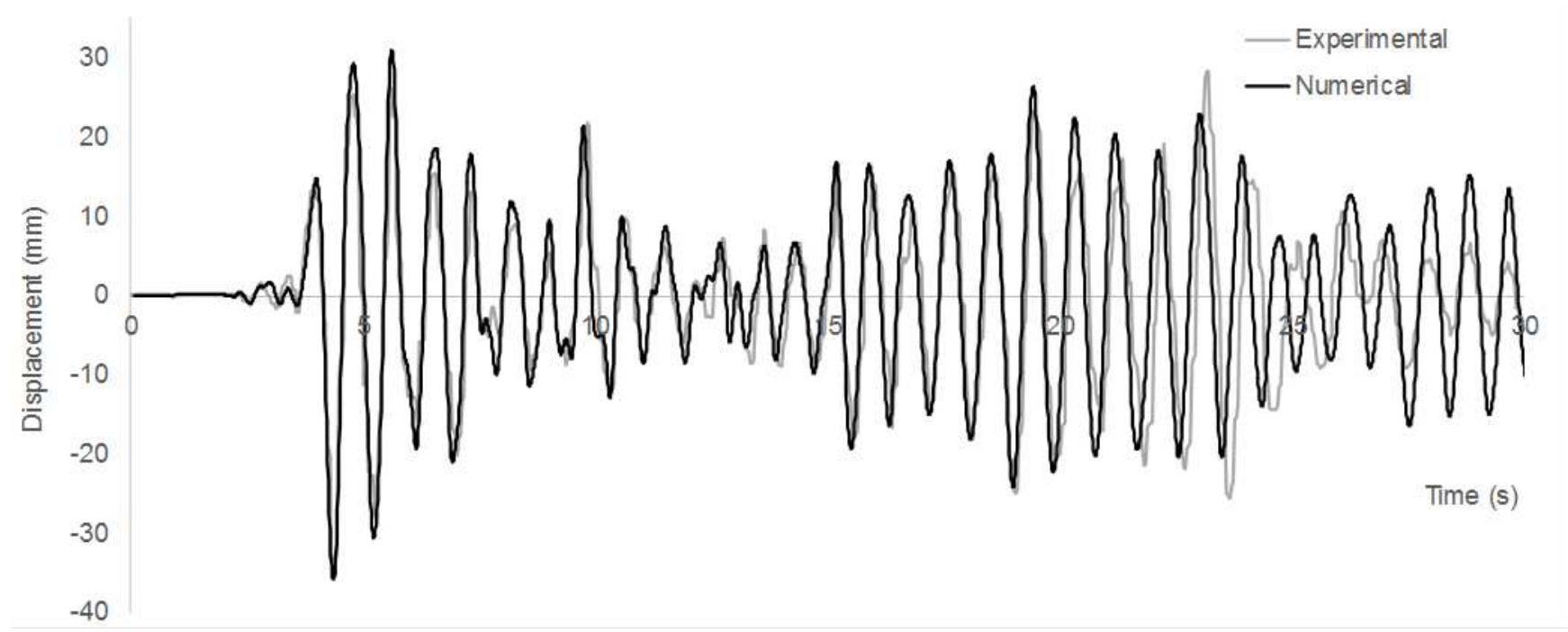

Fig. 12. Prototype building top floor displacement histories. Modified Taft ground motion. Model 4

Plots from Fig. 12 show a satisfactory agreement between the experimental and simulated results; noticeably, the higher discrepancies correspond to the last time interval (25-30 s), where more error is expected, given that important damage in the frame has been cumulated along the analysis. This fit confirms the correct estimation of the tested structure parameters, and the ability of the developed model to reproduce flexural failure. Regarding flexural-shear and flexural-shear-axial failure modes, the coincidence with the observations of [Bracci et al. 1995] can be read as a confirmation of the model reliability. After this verification, next section presents an Incremental Dynamic Analysis of the Prototype Building.

\section{Incremental Dynamic Analysis of the Prototype Building}

A 2D inner frame in the short direction of the building is analyzed. Due to cracking, the effective flexure stiffness is estimated as $0.4 E I_{\mathrm{g}}$ for beams. The obtained fundamental period in the analyzed direction is $1.148 \mathrm{~s}$. The Incremental Dynamic Analysis (IDA) is carried out for the same input considered in [Bracci et al. 1995]. In the numerical simulation, damping is represented as in the Van Nuys building; the damping ratio is also 5\%. In the most critical analyses, the time step is $0.00002 \mathrm{~s}$.

Fig. 13 displays two IDA curves in terms of maximum interstory drift ratio vs. spectral acceleration for the building fundamental period $\left(S_{\mathrm{a}}\left(T_{1}\right)\right)$; these curves correspond to Models 1 and 4 . Until the maximum intensity is achieved, both responses are very similar; later, they become flat for approximately $S_{\mathrm{a}}\left(T_{1}\right)=0.49$ and $0.42 \mathrm{~g}$, respectively. The difference between these two flat branches corresponds to the margin between the flexuralshear and flexural-shear-axial failure modes. 


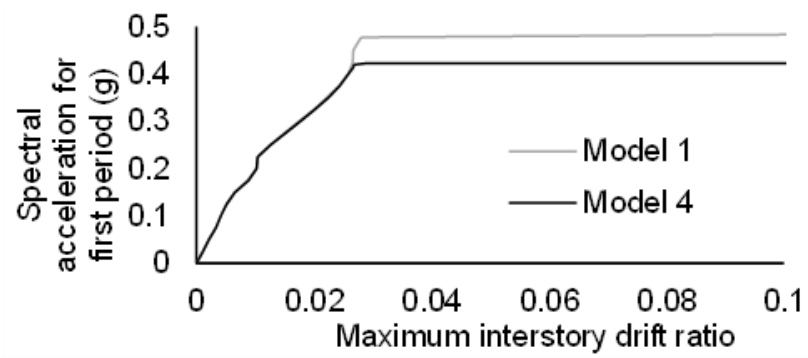

Fig. 13. IDA curves of the prototype building. Taft ground motion. Models 1 and 4

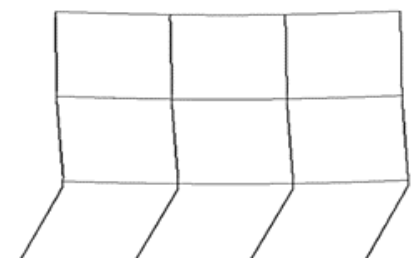

(a) Model 1

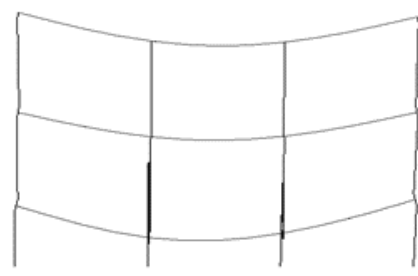

(b) Model 4

Fig. 14. Collapse modes of the prototype building. Taft ground motion. Models 1 and 4

Fig. 14 depicts the collapse modes for Models 1 and 4. Model 1 (Fig. 14.a) predicts sidesway collapse due to flexure hinging of the first-floor columns at $S_{\mathrm{a}}\left(T_{1}\right)=0.5 \mathrm{~g}$ (Fig. 13), while Model 4 (Fig. 14.b) detects an earlier flexure-shear deterioration of the first-floor columns followed by flexure-shear-axial failure (loss of axial carrying capacity) of the inner first-floor columns at $S_{\mathrm{a}}\left(T_{1}\right)=0.425 \mathrm{~g}$ (Fig. 13). Similarly to Fig. 3.d and Fig. 7.d, subsequent larger deformation states cannot be captured. However, Fig. 13 shows that this state can be considered as vertical collapse [Alfarah 2017]. Noticeably, since the transverse reinforcement ratio is low and the columns sections are small, the margin between the flexure-shear and flexure-shear-axial deterioration is smaller than in the the Van Nuys building.

Fig. 15 displays, similarly to Fig. 5 and Fig. 9, plots of axial force vs. story drift for the first-floor columns; the displayed plots correspond to the final time-history analysis using Model $4\left(S_{\mathrm{a}}\left(T_{1}\right)=0.425 \mathrm{~g}\right.$, Fig. 13). Fig. 15

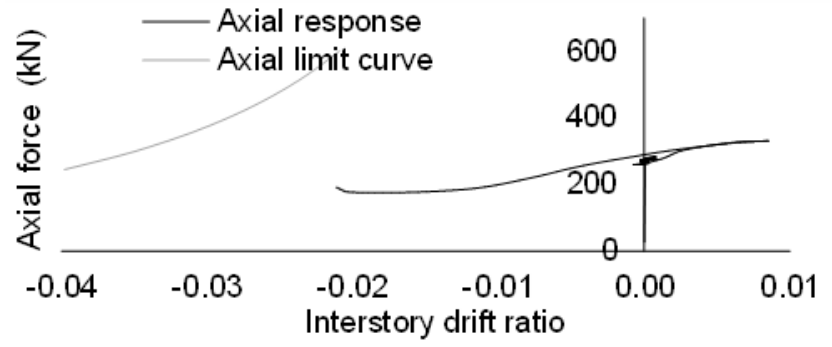

(a) Column C1 (left column in Fig. 14)

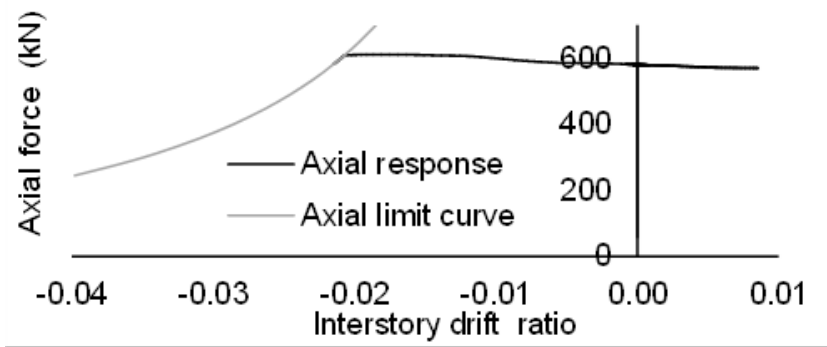

(b) Column C2 (second column in Fig. 14)

confirms that columns $\mathrm{C} 2$ and $\mathrm{C} 3$ reach their axial limit curves. 


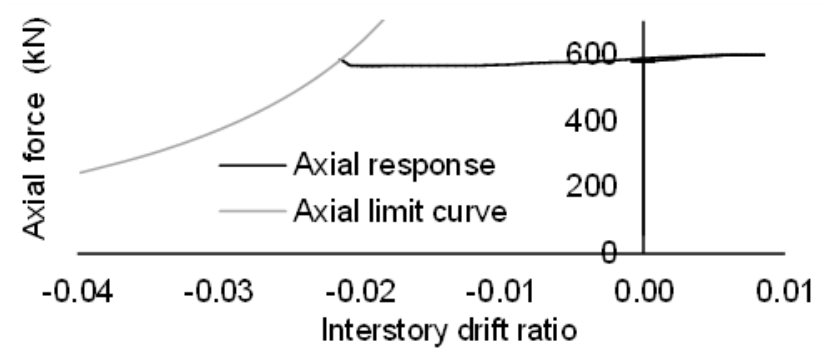

(c) Column C3 (third column in Fig. 14)

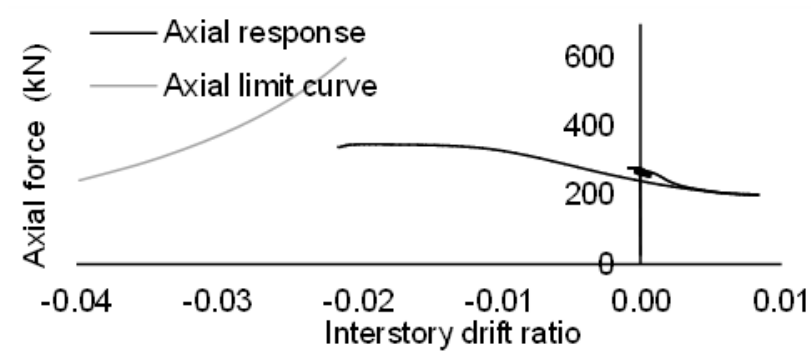

(d) Column C4 (right column in Fig. 14)

Fig. 15. Axial force of first-floor columns vs. drift for the prototype building. Taft ground motion. Model 4

As in the analysis of the Van Nuys building (Fig. 10), the shear force of the first-floor columns is compared with their shear capacity [Alfarah 2017]; it is concluded that the shear forces do not exceed the corresponding strength.

\section{Conclusions}

This paper proposes simulating the nonlinear dynamic behavior of 2-D RC building frames under severe seismic excitation with a combination of existing models. These combined models are selected to capture the most relevant issues while maintaining their computational efficiency. The nonlinear beams behavior is described with concentrated plasticity. Conversely, the columns are more accurately represented by using distributed plasticity and taking into consideration the flexure hinging, flexure-shear, flexure-shear-axial, and compressive deterioration modes, and the reinforcement bond-slip. The developed model is particularly suitable for nonductile RC frames, given that the condition "strong column-weak beam" is not fulfilled and, hence, the columns receive most of the damage. The capacity of the developed model is verified in an existing non-ductile building and in a prototype building that had been intentionally designed without any seismic consideration. As well, the developed model is validated with tests of a reduced-scale laboratory model of that prototype building.

The obtained results show that the developed model, despite its moderate computational cost, detects and reproduces accurately the deterioration modes that are unseen by the simplified models (that are commonly employed in earthquake engineering) are blind to. Comparison with the results from those simplified models highlights the importance of such hidden failure modes in the behavior of each element and in the overall collapse mechanisms. As well, the developed model has proven able to simulate accurately an experiment on a reduced scale model of the aforementioned prototype building. Further analyses using a representative set of seismic inputs are necessary to quantify the errors produced by the oversimplified models.

Finally, it is worth emphasizing that this research corroborates that the oversimplified models can lead to significant non-conservative over-estimation of the structural capacity.

\section{Acknowledgements}

This work has received financial support from Spanish Government under projects BIA2014-60093-R, MAT2014-60647-R and CGL2015-6591 and from European Commission under projects ERC-2012-AdG320815 and PIRSES-GA-2013-612607. These supports are gratefully acknowledged.

\section{References}

- Alfarah B (2017) Advanced Computationally Efficient Modeling of RC Structures Nonlinear Cyclic Behavior, Doctoral dissertation, Technical University of Catalonia.

- Alfarah B, López-Almansa F, Oller S (2017). New methodology for calculating damage variables evolution in Plastic Damage Model for RC structures, Engineering Structures 132:70-86. 
- Alfarah B, Delso Murcia J, López-Almansa F, Oller S (2017). RC Structures Cyclic Behavior Simulation with a Model integrating Plasticity, Damage and Bond-Slip, Earthquake Engineering and Structural Dynamics (DOI: 10.1002/eqe.2974).

- ASCE 41 (2013) Seismic Evaluation and Retrofit of Existing Buildings, American Society of Civil Engineering.

- Aslani H, Miranda E (2005) Probabilistic Earthquake Loss Estimation and Loss Disaggregation in Buildings. Blume Earthquake Engineering Center, Stanford University.

- ATC 78-1 (2015) Evaluation of the methodology to select and prioritize collapse indicators in older concrete. Applied Technology Council.

- Aycardi LE, Mander JB, Reinhorn AM (1994) Seismic resistance of reinforced concrete frame structures designed only for gravity loads: Experimental performance of subassemblages, ACI Structural Journal, 91(5):552-563.

- Baradaran Shoraka M, Elwood KJ (2013a) Mechanical Model for Non Ductile Reinforced Concrete Columns. Journal of Earthquake Engineering, 17(7):937-957.

- Baradaran Shoraka M, Yang TY, Elwood KJ (2013b) Seismic loss estimation of non-ductile reinforced concrete buildings. Earthquake Engineering \& Structural Dynamics, 42:297-310.

- Berry M, Parrish M, Eberhard M (2004) PEER Structural Performance Database User's Manual, (www.ce.washington.edu/ peera1), Pacific Earthquake Engineering Research Center.

- Bracci JM, Reinhorn AM, Mander JB (1995) Seismic resistance of reinforced concrete frame structures designed for gravity loads: Performance of structural system. ACI Structural Journal 92(5):597-608.

- De Risi MR, Ricci P, Verderame GM (2017) Modelling exterior unreinforced beam-column joints in seismic analysis of non-ductile RC frames, Earthquake Engineering and Structural Dynamics 46:899-923.

- Elwood KJ, Moehle JP (2003) Shake Table Tests and Analytical Studies on the Gravity Load Collapse of Reinforced Concrete Frames. PEER Report 2003/01. Pacific Earthquake Engineering Research Center.

- Elwood KJ (2004) Modelling deteriorations in existing reinforced concrete columns. Can. J. Civ. Eng. 31:846-859.

- Elwood KJ, Moehle JP (2006) Idealized Backbone Model for Existing Reinforced Concrete Columns and Comparisons With FEMA 356 Criteria. The Structural Design of Tall and Special Buildings 15:553-569. DOI: 10.1002/tal.382.

- Elwood KJ, Eberhard MO (2009) Effective Stiffness of Reinforced Concrete Columns. ACI Structural Journal, 106(4):476-484.

- FEMA P695 (2009) Quantification of Building Seismic Performance Factors, Federal Emergency Management Agency.

- Haselton CB, Deierlein GG (2007) Assessing Seismic Collapse Safety of Modern Reinforced Concrete Frame Buildings, Technical Report No. 2007/08, Pacific Earthquake Engineering Research Center.

- Haselton CB, Liel AB, Taylor-Lange S, Deierlein GG (2008) Beam-Column Element Model Calibrated for Predicting Flexural Response Leading to Global Collapse of RC Frame Buildings, Pacific Earthquake Engineering Research Center.

- Haselton CB, Liel AB, Deierlein GG (2009) Simulating Structural Collapse Due To Earthquakes: Model Idealization, Model Calibration, and Numerical Solution Algorithms. ECCOMAS Thematic Conference on Computational Methods in Structural Dynamics and Earthquake Engineering, Rhodes, Greece.

- Ibarra LF, Medina RA, Krawinkler H (2005) Hysteretic models that incorporate strength and stiffness deterioration, Earthquake Engineering and Structural Dynamics, 34(12):1489-1511.

- Jeon JS, DesRoches R, Brilakis I (2012) Aftershock Fragility Curves for Damaged Non-Ductile Reinforced Concrete Buildings. $15^{\text {th }}$ World Conference on Earthquake Engineering, Lisbon, Portugal.

- Jeon JS, Lowes LN, DesRoches R, Brilakis I (2015) Fragility curves for non-ductile reinforced concrete frames that exhibit different component response mechanisms. Engineering Structures 85:127-143.

- Kato D, Ohnishi K (2001) Axial Load Carrying Capacity of R/C Columns under Lateral Load Reversals. Third USJapan Workshop on Performance-Based Earthquake Engineering Methodology for Reinforced Concrete Building Structures 231-239. 
- Krawinkler H (2005) Van Nuys Hotel Building Testbed Report: Exercising Seismic Performance Assessment, Technical Report 2005/11, Pacific Earthquake Engineering Research Center.

- Liel AB (2008) Assessing the Collapse Risk of California's Existing Reinforced Concrete Frame Structures: Metrics for Seismic Safety Decisions. Doctoral Dissertation, Stanford University.

- McKenna F, Fenves GL, Scott MH, Jeremic B (2000) Open System for Earthquake Engineering Simulation (OpenSees). Pacific Earthquake Engineering Research Center, Berkeley.

- Nakamura T, Yoshimura M (2002) Gravity load collapse of reinforced concrete columns with brittle deterioration modes. Journal of Asian Architecture and Building Engineering, 1(1):21-27.

- Priestley MJN, Verma R, Xiao Y (1994) Seismic shear strength of reinforced concrete columns. Journal of Structural Engineering, 120(8):2310-2329.

- Pujol S, Ramírez JA, Sozen MA (1999) Drift Capacity of Reinforced Concrete Columns Subjected to Cyclic Shear Reversals. American Concrete Institute, SP-187:255-274.

- Scott BD, Park R, Priestley MJN (1982) Stress-Strain Behavior of Concrete Confined By Overlapping Hoops At Low and High Strain Rates. J. American Concrete Institute, 79:13-27.

- Sezen H (2002) Seismic response and modeling of reinforced concrete building columns. Doctoral Dissertation, University of California Berkeley.

- Vamvatsikos D, Cornell CA (2002) Incremental dynamic analysis. Earthquake Engineering \& Structural Dynamics, 31:491-514.

- Vamvatsikos D, Jalayer F, Cornell CA (2003) Application of Incremental Dynamic Analysis to an RC-Structure. FIB Symposium on Concrete Structures in Seismic Regions, Athens.

- Yavari S, Lin SH, Elwood KJ (2008) Study on collapse of flexure-shear-critical reinforced concrete frames. $14^{\text {th }}$ World Conference on Earthquake Engineering, Beijing, China. 